\title{
TRANSFORMACCÕES GLOBAIS, POTÊNCIAS EMERGENTES E COOPERAÇÃO SUL-SUL: desafios para a cooperação europeia
}

\author{
Bruno Ayllón Pino*
}

\begin{abstract}
A União Europeia (UE) e seus Estados Membros enfrentam o desafio de adaptar sua política de cooperação para o desenvolvimento a um mundo marcado por rápidas mudanças na criação e distribuição da riqueza e na difusão do poder. A ascensão dos países emergentes, o auge da Cooperação Sul-Sul (CSS), os avanços na luta contra a pobreza em Países de Renda Média (PRM), ou o impacto traumático da crise nos países da Organização para a Cooperação e o Desenvolvimento Econômico (OCDE), são fatores que originarão grandes transformações estruturais e obrigarão uma modificação do sentido e da prática da cooperação europeia. Â negociação das perspectivas financeiras para 2014-2020 e a reforma nos instrumentos de cooperação da Comissão Europeia (CE) constituem uma primeira resposta a essas mudanças. O maior interesse demonstrado pela CSS em alguns Estados Membros e o desencadeamento de iniciativas de cooperação triangular com países como o Brasil representam um sinal da busca de horizontalidade e complementaridade na cooperação europeia com os países latino-americanos.

PALAVRAS-CHAVE: países emergentes, cooperação Sul-Sul, instrumentos de cooperação, cooperação triangular, parceria estratégica UE-Brasil.
\end{abstract}

\section{AS TRANSFORMAÇÕES GLOBAIS E SEU IMPACTO NA COOPERAÇÃO EUROPEIA}

A difusão do poder mundial e a ascensão econômica e política dos países emergentes constituem duas das principais transformações nas relações internacionais do Século XXI. Com efeito, tanto a emergência de novos poderes no sistema internacional como a importância crescente de uma nova classe média de países têm consequências na distribuição do poder em escala global e em outras dimensões, como a Cooperação Internacional para o Desenvolvimento (CID). À medida que muda a configuração internacional, com países em declive e em ascensão, são incrementadas as possibilidades e oportunidades de se ampliar o leque

* Doutor em Relações Internacionais. Pesquisador e professor associado ao Instituto Universitario de Desenvolvimento e Cooperação da Universidade Complutense de Madri, Espanha. É bolsista do Programa Nacional de Pesquisa para o Desenvolvimento do Instituto de Pesquisa Econômica Aplicada do Brasil. As opiniões apresentadas neste texto não comprometem as instituições às quais o autor se vincula. Os erros e inexatidões que possam ser encontrados são de responsabilidade exclusiva do autor Calle Donoso Cortes, 656 drcha. Moncloa. 28015. Madrid - Espanha.brunespa@gmail.com das formas "tradicionais" de cooperação, derivadas das responsabilidades que os emergentes assumem.

O fato de a UE ter estabelecido parcerias estratégicas com China, Índia, Brasil, Rússia, México e África do Sul reflete a importância atribuída à relação com essas potências emergentes. Os impactos desses movimentos tectônicos nas estruturas profundas do sistema internacional não se limitam ao campo da economia e da política. Sua repercussão se estende ao âmbito da CID, delineando um desafio para a UE e seus Estados Membros (Grimm, et al, 2009).

Os países emergentes menos afetados pela crise em seu crescimento econômico multiplicaram sua capacidade de influência nos assuntos mundiais, convertendo-se em global players que contribuem, através do financiamento e execução de programas e projetos, para o desenvolvimento de outros países e para as atividades de organismos multilaterais. Os avanços econômicos e sociais desses emergentes e de outros PRM geram oportunidades para a ampliação dos volumes e das modalidades da cooperação, que não se limitam apenas ao oferecimento de ajuda, pois integram 
outras dimensões como o comércio, os investimentos e os intercâmbios tecnológicos.

Esses países emergentes, em sua maioria PRM e, por isso, países ainda em desenvolvimento, que recebem Assistência Oficial ao Desenvolvimento (AOD), diversificaram sua oferta de cooperação a partir de seus próprios modelos e do incremento de seu CSS. Assim, a prática de cooperação se enriqueceu com novas modalidades, como a cooperação triangular, e se desenvolveram programas de assistência técnica em novos espaços regionais, em países e setores de atuação abandonados pelos doadores tradicionais, por exemplo, com iniciativas de desenvolvimento rural na América Latina e Caribe (Programa Pró-Horta da Argentina), ou na África (Programa Pró-Savana do Brasil e Programa e Projeto Pan-africano E-Network da Índia), ou com vigorosas ações em campos de grande impacto, como a saúde global, redesenhando e modificando as coordenadas da cooperação e o desenvolvimento na provisão de certos bens públicos internacionais (GHSi, 2012).

Agrupar esses países em classificações é um exercício complicado, devido à falta de critérios consensuais e à sua variedade, determinada pela distinta evolução de seus processos de desenvolvimento, bem como pelas diferentes estruturas organizativas de canalização dos recursos oferecidos e das ações de cooperação realizadas. Alguns acrescentar a Rússia, considerada uma “doadora reemergente”), ${ }^{1}$ os “doadores árabes” (Kuwait, Arábia Saudita e Emirados Árabes Unidos) e os "subministradores de Cooperação Sul-Sul para o Desenvolvimento", dentro dos quais encontramos potências emergentes como Brasil, China, Índia e África do Sul (os mais importantes quantitativamente nesse grupo e aos quais nos referiremos neste artigo) e outros PRM e economias emergentes como Chile, Colômbia, Malásia, México, Tailândia e Venezuela (Zimmermann; Smith, 2011).

Diferentes estimativas, que devem ser tomadas com precaução, dadas as dificuldades de quantificar a cooperação dos emergentes, devido a falhas na informação e à ausência de parâmetros homogêneos, situam seus aportes monetários em uma faixa que oscila entre 11.000 e os 41.700 milhões de dólares, isso é, entre 8 e $31 \%$ do total dos fluxos globais registrados em 2008, constituindo um recurso complementar ao da AOD (Walz; Ramachandran, 2011).

Nesse panorama, destacam-se China, Arábia Saudita e Venezuela (2.000 milhões de dólares, respectivamente), as agências de países árabes (1.000 milhões) e Índia (750 milhões). Outros cálculos combinados de diferentes instituições elevam a ajuda árabe até 5.500 milhões de dólares e incluem a Turquia, com quase oitocentos milhões (ECOSOC, 2008). Por sua vez, o CAD/OCDE acres-

Tabela 1 - Cooperação Brasileira para o Desenvolvimento Internacional

\begin{tabular}{lccccccc}
\hline & $\mathbf{2 0 0 5}$ & $\mathbf{2 0 0 6}$ & $\mathbf{2 0 0 7}$ & $\mathbf{2 0 0 8}$ & $\mathbf{2 0 0 9}$ & $\begin{array}{c}\text { Total } \\
\text { \% em relação } \\
\text { ao total }\end{array}$ \\
\hline Assistência humanitária & 0,7 & 3,3 & 17,9 & 15,6 & 43,5 & 81 & 5,04 \\
\hline Bolsas de estudos para estrangeiros & 35,4 & 33,6 & 31,7 & 37 & 22,2 & 160 & 9,95 \\
\hline Cooperação técnica, científica e tecnológica & 17,5 & 19,5 & 20 & 30,7 & 48,8 & 136,7 & 8,50 \\
\hline Contribuições para organismos internacionais & 189 & 303,5 & 250,6 & 239,5 & 247,6 & 1230,4 & 76,50 \\
\hline Total & 242,9 & 359,9 & 320,2 & 322,9 & 362,2 & 1608,3 & $100 \%$ \\
\hline
\end{tabular}

Nota: valores constantes em milhões de dólares convertidos a partir do valor do Real, usando a taxa média de câmbio

PTAX-BCB de 2009. (IPEA ; ABC, 2010, p.21).

autores propõem distinguir entre os "doadores emergentes" (um grupo heterogêneo de 16 países, dos quais 12 são novos membros da UE, e outros 4 que não pertencem ao bloco, aos quais se deve
${ }^{1}$ Os países da UE que seguem critérios similares, em sua cooperação, aos estabelecidos pelo Comitê de Ajuda ao Desenvolvimento da OCDE (CAD/OCDE) são Bulgária, República Checa, Chipre, Estônia, Hungria, Lituânia, Letônia, Malta, Polônia, Romênia, Eslovênia e República Eslovaca. Também seguem esses parâmetros do CAD/ OCDE e referem-se à sua cooperação como AOD Israel, Islândia, Turquia e Liechtenstein. 
centa a Rússia em seus informes, com aportes anuais de 200 milhões de dólares. No que se refere ao Brasil, segundo cálculos do IPEA, a cooperação brasileira para o desenvolvimento internacional haveria investido, entre 2005 e 2009, em torno de 1600 milhões de dólares em contribuições multilaterais, programas de cooperação técnica, assistência humanitária e ajudas de estudo para estrangeiros (IPEA ; ABC, 2010, p.21).

Segundo a ONU, $22 \%$ da

CSS global são canalizados por via multilateral, e mais de $90 \%$ são oferecidos sob a forma de ajuda programável vinculada a iniciativas de cooperação técnica. Isto é, $75 \%$ se destinam ao financiamento de programas e projetos, crescendo rapidamente a ajuda orçamentária e humanitária (DESA; ONU, 2010). Geograficamente, os emergentes privilegiam o oferecimento de ajuda a países vizinhos e situ- Fonte: DAC; OCDE (2012) am sua provisão no marco de mecanismos de cooperação e integração regional, devido ao maior grau de interdependência e os vínculos mais estreitos entre seus membros. São poucos os países que têm recursos e capacidade de projetar sua cooperação fora de seu entorno mais próximo, com exceção da China e, em menor medida, do Brasil e da Índia. No caso particular desses três países,

a fragmentação burocrática e a falta de agências coordenadoras centrais capazes de planejar, monitorar e avaliar a cooperação no nível nacional [...] impedem que se tenha um conhecimento mais completo e preciso de montantes, distribuição e objetivos dessa cooperação." (Mello e Souza, 2012, p. 93).

Para além dos indicadores habituais (PIB, extensão, população, comércio, investimentos, patentes, presença global, etc.), que situam os emergentes e os PRM como países que não necessitam cooperação, o certo é que esses países permanecem sendo muito sensíveis a choques externos, continuam apresentando importantes fragilidades institucionais, concentram enormes bolsões de pobreza e são peças-chave para o fornecimento de bens públicos regionais e internacionais. A maioria se qualifica ainda como "países em desenvolvimento" nas listas de países receptores do CAD/ OCDE, e essa condição os habilita, em diferentes graus e medidas, como beneficiários de AOD, em alguns casos com montantes volumosos, entre os 50 principais receptores a partir de 1970.

Tabela 2 - AOD recebida por países emergentes entre 2007 e 2010

\begin{tabular}{lrrrr}
\multicolumn{5}{c}{ (em milhões de dólares) } \\
País emergente & $\mathbf{2 0 0 7}$ & $\mathbf{2 0 0 8}$ & $\mathbf{2 0 0 9}$ & $\mathbf{2 0 1 0}$ \\
\hline Brasil & 331 & 458 & 337 & 661 \\
China & 1.586 & 1.450 & 1.129 & 673 \\
Índia & 1.339 & 2.073 & 2.500 & 2.763 \\
África do sul & 841 & 1.094 & 1.075 & 1.033 \\
Turquia & 845 & 1.119 & 1.362 & 1.044 \\
Colômbia & 745 & 964 & 1.059 & 915 \\
Nigéria & 1.967 & 1.265 & 1.657 & 2.049 \\
México & 107 & 141 & 184 & 484 \\
Vietnam & 2.687 & 2.535 & 3.732 & 2.879 \\
Indonésia & 841 & 1.139 & 1.047 & 1.323 \\
\hline
\end{tabular}

O deslanchar de dinâmicos e inovadores programas de cooperação pode ser considerado como manifestação do soft power desses países. Esse componente moderado de sua projeção exterior lhes permite ampliar sua capacidade de persuasão e ganhar adesões a seus interesses em outros países em desenvolvimento, a partir de um exercício de atração positiva baseado em três fontes principais: valores políticos, cultura e política exterior (Nye, 2010). A cooperação para o desenvolvimento pode ser um dos instrumentos do soft power, por sua vantajosa relação custo/benefício e pelos rápidos retornos obtidos sob a forma de prestígio e influência.

Dessa perspectiva, e sem negar a existência de motivações solidárias ou altruístas, a CSS se subordina, com um caráter geral, às políticas exteriores, com um marcado caráter instrumental, limitado aos benefícios esperados pelos países individualmente, e não tanto do coletivo do mundo em desenvolvimento, articulado em torno de "de- 
mandas de mudança comuns” (Kern; Weistaubb, 2011, p.93).

Outras motivações incluiriam a busca de novos mercados e oportunidades econômicas para incrementar as margens de manobra desses países, diversificando suas opções internacionais, ao ampliarem suas relações e alcançarem maiores níveis de autonomia (política, econômica e decisória) com o objetivo de produzir mudanças na distribuição do poder mundial e em suas instituições e regimes. Finalmente, existe um componente de prestígio que se traduz nos esforços para construir uma imagem positiva internacional. Definitivamente, a colaboração desses países emergentes no desenvolvimento de outros pode ser considerada um subproduto de suas relações exteriores, mas não sua força motriz (Sidiripoulos, 2011).

Uma das dimensões mais relevantes da política exterior desses países emergentes e de renda média foi sua vontade de contribuir para o desenvolvimento internacional com uma perspectiva transformadora, vinculada à redução das assimetrias que caracterizam o sistema mundial. A decisão de colaborar ativamente nas tarefas para o cumprimento dos Objetivos de Desenvolvimento do Milênio (ODM) se relaciona com a elaboração de um conjunto variado de propostas políticas que pretendem, através da ação coletiva em coalizões Sul-Sul, desencadear mudanças nas re-

${ }^{2}$ Declaracões da embaixadora Maria Edileuza Fontenele Reis, subsecretária geral de política do Ministério das Relações Exteriores do Brasil. O Estado de São Paulo. "Os BRICS querem reformas no FMI e no Banco Mundial”, 28 mar. 2012
Essas propostas políticas foram acompanhadas do oferecimento de apoios materiais, investimentos produtivos, comércio de bens e serviços e soluções técnicas para contribuir na resolução das carências de outros países em desenvolvimento. Em alguns casos, a presença internacional ativa desses países e a materialização de um discurso e de uma prática qualificada como "diplomacia da solidariedade" incentivaram a demanda por seus produtos e conhecimentos em setores como saúde, energia, educação, agricultura, políticas sociais ou fortalecimento da administração pública, para citar alguns. Os países emergentes e outros países em desenvolvimento atuam, assim, como "agentes dinamizadores da distribuição do poder”, convertendo questões como a reforma das Nações Unidas ou das Instituições Financeiras Internacionais em objetivos centrais de sua política exterior (Barbé, 2010, p.30). A busca de maiores espaços nas instituições multilaterais e o reconhecimento das vantagens que derivam da participação nelas, sem abdicar da defesa de seus interesses nacionais e de manter uma presença soberana no mundo, são os traços característicos de seu comportamento em diferentes regimes internacionais, com uma forte marca revisionista que não delineia mudanças radicais das regras do jogo (Barbé, 2010).

Dessa forma, eles buscam reverter a tendência histórica de sua participação no sistema multilateral, habitualmente caracterizada por uma agenda negativa, centrada na articulação de coalizões de veto, pela passividade dos menos dotados de capacidades materiais e vontade política, e por uma forte inclusão institucional, combinada com uma grande exclusão decisória, em aqueles com mais recursos de poder.

As alianças constituídas entre esses países, tais como o fórum IBSA (Índia, Brasil e África do Sul), o G-20 da reunião de cúpula da OMC em Cancun (2003) ou a institucionalização dos encontros anuais do grupo dos BRICS (Brasil, Rússia, Índia e África do Sul) e as siglas inventadas por acadêmicos e consultores internacionais que modificam (BASIC, que exclui a Rússia) ou ampliam o número de países emergentes, como BRICSAM 
(que acrescenta o México aos BRICS), os EAGLES (sigla utilizada pelo grupo de estudos do Banco Bilbao Vizcaia para referir-se a um grupo de dez economias emergentes ou Emerging and Growth Leading Economies) ou os CIVETS (Colômbia, Indonésia, Vietnam, Egito, Turquia e África do Sul) demonstram o estado de ebulição do mundo que emerge no século XXI e como, no contexto da evolução da governança global, surge uma nova geração de atores do desenvolvimento, como "classe média incipiente" (Schulz, 2010).

Essa vontade de articulação multilateral dos países emergentes e de outros PRM para melhorar as regras do jogo a favor do desenvolvimento internacional bem como o estabelecimento de coalizões e alianças são potencializados com sua participação ativa nos mecanismos de governança e com o renovado protagonismo da cooperação que oferecem a outros países do Sul Global. Todos esses elementos são realidades que devem ser situadas num contexto mais amplo: o da transformação das relações internacionais pela ascensão econômica e política dos países emergentes.

Em sua dimensão econômica, diferentes estimativas afirmam, por exemplo, que os países do BRICS e outros emergentes concentrarão, no ano de 2030 , cerca de $60 \%$ do PIB mundial. As projeções assinalam que o PIB da China ultrapassará o dos Estados Unidos no ano de 2025, e o do Brasil o do Japão em 2050, momento em que a Rússia, o México, a Indonésia e a Turquia se igualarão, quanto a seu peso econômico, a Alemanha, França, Reino Unido e Itália (Milani, 2011, p.55). Assim, "a nova geografia do crescimento" vem marcada pela intensidade dos intercâmbios de todo tipo entre os países em desenvolvimento, representando um componente central no processo de mudança da criação e distribuição da riqueza (OCDE, 2010).

O último informe do Secretário Geral da ONU sobre o estado da CSS destacou a liderança dos países emergentes na nova geografia do crescimento mundial, demonstrando sua notável resistência frente à crise econômica que melhorou a riqueza econômica dos países mais pobres. Essas mudanças, propiciadas pelo ímpeto das relações Sul-Sul, teriam promovido modificações profundas na estrutura das relações internacionais e estariam produzindo resultados em termos de desenvolvimento graças ao reconhecimento das oportunidades e capacidades dos países do Sul e ao aumento da demanda por sua cooperação. Dessa maneira, as relações Sul-Sul estão promovendo mudanças profundas nas estruturas das relações internacionais e começaram a produzir resultados em matéria de desenvolvimento, pois alguns países do hemisfério Sul constituem, na atualidade, uma força poderosa na economia mundial.

Assim, entre 1990 e 2008, o comércio mundial quadruplicou, enquanto o comércio Sul-Sul multiplicou-se 20 vezes em relação a seu nível inicial no mesmo período. Em 2008, os países em desenvolvimento representavam cerca de $30 \%$ do comércio mundial e quase $3 / 4$ do crescimento global. Por outro lado, as economias em desenvolvimento atraíram, cada vez mais, investimento e capital privado, de 110.000 milhões de dólares (em 2008) a uma estimativa (em 2020) de $650.000 \mathrm{mi}-$ lhões (Nações Unidas, 2011).

Em sua dimensão política, esse processo, qualificado como "multipolaridade emergente", é resultante da acumulação de capacidades e de recursos materiais, por força do reconhecimento de outros Estados da sua condição de potências emergentes. A partir desses dois fatores, capacidades e reconhecimento, configuraram-se as estratégias de atuação dos emergentes (Barbé, 2010, p.31). As potências tradicionais e os países da OCDE responderam a esse desafio através de um processo gradual de integração desses países nos diferentes mecanismos e fóruns globais (G20 - financeiro), registrando-se um maior ativismo dos emergentes nos debates sobre a crise econômica, a mudança climática, os processos de paz e estabilização pósconflito, o regime nuclear, o comércio ou a reforma das instituições financeiras e políticas multilaterais. Em consequência, países como Brasil, Índia ou África do Sul passam a participar de diferentes "clubes de poderes " para a governança global, especialmente o G20, considerado por alguns ana- 
listas como "lugar de observação e experimentação dos novos modos e códigos das relações internacionais" e das novas formas de cooperação (Kadah, 2012, p.1; Postel-Vinay, 2011, p.133).

Os BRICS e outros emergentes recusaram-se a ser meros espectadores nesses fóruns, administrando com eficácia a importância de sua presença para aumentar seu impacto. Mesmo não atuando como um bloco homogêneo - como mostra a falta de consenso no apoio a um só candidato à presidência do Banco Mundial-, influem com frequência nos resultados das decisões multilaterais, compartilhando alguns objetivos ou coordenando antecipadamente sua ação para conduzir a agenda e alterar os termos das propostas. A convocação realizada pelos ministros da economia da Argentina e do Brasil a seus pares da UNASUL, em novembro de 2011, com o objetivo de coordenar posições no G20 e se fortalecerem frente à crise econômica é um bom exemplo disso. Mais recentemente, a proposta de constituir um Banco Sul-Sul, que foi apresentada na reunião de cúpula dos BRICS de Nova Delhi (27 e 28 de março de 2012), é uma evidência do caráter proativo das potências emergentes.

As contribuições dos emergentes e de outros PRM ao desenvolvimento internacional estão sendo especialmente intensas em âmbito multilateral, em que não poupam esforços para colaborar criativamente no cumprimento do $8^{\circ} \mathrm{ODM}$ : "Fotilaterais e na aposta pra fazer do G20 um novo centro da cooperação econômica internacional.
Em segundo lugar, no âmbito comercial, os emergentes tiveram um papel central nas negociações para a liberalização do setor agrícola na OMC (Reunião de Cúpula de Cancún, 2003) e no impulso ao comércio Sul-Sul, concebido não apenas como troca de mercadorias por divisas, senão como "intercâmbio de conhecimentos e capacidades que ajudam a garantir a entrada competitiva e sustentável de países menos avançados no mercado internacional" (Biato, 2009). Os emergentes são muito dinâmicos no capítulo da ajuda para o comércio, oferecendo cooperação técnica a países em desenvolvimento e oferecendo financiamento para modernizar infraestruturas que aumentem a competitividade exportadora. Mais recentemente, empenharam-se em aprofundar o Sistema Global de Prioridades Comerciais entre Países em Desenvolvimento, concedendo acesso livre de tarifas e cotas a países de menor desenvolvimento relativo.

Em terceiro lugar, as energias de muitos países em desenvolvimento, emergentes e de renda média, especialmente ativos em promover mudanças na governança global, se voltaram para a reforma da ONU, para a ampliação de espaços no Conselho de Segurança ou para a aposta no fortalecimento do ECOSOC e de seu Fórum de Cooperação para o Desenvolvimento como a plataforma mais legítima e representativa para discutir os temas da eficácia da ajuda, frente à aposta dos países da OCDE nos Fóruns de Alto Nível que aconteceram em Paris, Accra e Busan. Em todos esses fóruns, a aposta foi pela geração das mudanças necessárias para promover uma ordem internacional mais democrática, justa e solidária.

A ênfase na geração de coalizões Sul-Sul parece produzir resultados positivos. A ideia axial que sustentou, nesses anos, a estratégia de inserção internacional dos emergentes foi a insuficiência da arquitetura clássica de governança global, agravada pela pressão de novos atores, o que gera tensões e acentua os desafios de legitimidade e eficácia das instituições multilaterais. Esses fóruns e organizações internacionais refletiriam realidades caducas e visões superadas, que não oferecem respostas satisfatórias aos desafios atuais. Nessas con- 
dições de bloqueio do multilateralismo tradicional, há mais potencial e preferência, entre os emergentes, por um "minilateralismo à la carte", no qual grupos de países impulsionam agendas compartilhadas (MRE, 2010). A atual crise econômica, cuja origem se encontra nos países desenvolvidos, tornou frágeis velhos conceitos de governança, especialmente no que se refere às relações com os países em desenvolvimento, "abrindo a porta ao reconhecimento por parte de governos e agentes econômicos de países industrializados da importância crescente das economias em desenvolvimento." (IPEA, 2010, p.154).

Definitivamente, assistimos, nos últimos anos, sobretudo no contexto da crise financeira atual, à crescente participação dos países emergentes e de renda média em "coalizões de geometria variável”. O sistema internacional e seus mecanismos insuficientes de governança atravessam uma fase de profundas transformações, sem que se defina ainda seu alcance e sem que se plasmem novas estruturas que respondam à complexidade $\mathrm{e}$ aos novos equilíbrios multipolares. As mudanças nas dinâmicas de poder, bem como o processo em curso de sua difusão e deslocamento vertical e horizontal, observáveis em âmbito mundial e na América Latina em particular, delineiam sérios e urgentes desafios à governança global $\mathrm{O}$ vigor das relações Sul-Sul, a criação de espaços autônomos para o concerto e a cooperação política entre países em desenvolvimento (como a Comunidade de Estados da América Latina e Caribe, CEALC, sem participação eurepeia ou norte-americana) e o impulso dos emergentes são transformações de profundo calado que impulsionarão os doadores tradicionais, especialmente os europeus, a uma redefinição de sua estratégias de cooperação.

\section{A UNIÃO EUROPEIA E O APOIO À COOPERA- ÇÃO SUL-SUL NA AMÉRICA LATINA}

A última década foi o cenário do auge renovado da CSS na América Latina e no mundo, entendendo-se como tal um fenômeno com três di- mensões interrelacionadas e, frequentemente, com fronteiras difusas. A) uma dimensão política que promove a constituição de âmbitos autônomos para a geração de perspectivas e práticas alternativas entre países em desenvolvimento. Esses espaços favorecem a comunicação e o estreitamento das relações bilaterais, propiciando a criação ou a revitalização de coalizões regionais (UNASUL, CEALC), inter-regionais (IBSA, reuniões de cúpula América do Sul - África), com o objetivo de incrementar a capacidade negociadora dos países em desenvolvimento e melhorar o ajuste e a coordenação de políticas (Santander, 2011). B) Uma dimensão técnica, considerada como um processo pelo qual dois ou mais países em desenvolvimento adquirem capacidades individuais e coletivas através de intercâmbios cooperativos em conhecimentos, experiências tecnológicas, expertises tecnológicas, que se traduzem em projetos e programas de cooperação. C) Uma dimensão econômica, realizada no âmbito comercial, financeiro e de investimentos entre países em desenvolvimento. Inclui formas de cooperação macroeconômica e se associa a processos de integração regional.

A América Latina é a região do mundo onde as experiências da CSS foram mais intensas, dinâmicas e pujantes, registrando avanços e experiências positivas na sua articulação em marcos de debate regional e multilateral. Alguns dos principais marcos da história da CSS foram produzidos na região. O conceito de Cooperação Técnica entre Países em Desenvolvimento (CTPD) foi fruto da Conferência de Buenos Aires (1978) que, promovida pela ONU, reuniu 138 países e desencadeou a adoção do Plano de Ação de Buenos Aires (PABA). A CSS aspira a se tornar, na América Latina, uma referência para outros países em desenvolvimento que buscam mais autonomia e compartilhar soluções em bases horizontais. Os Estados latino-americanos dirigem a CSS para países mais próximos que lhes despertem particular interesse, por motivos culturais, políticos, históricos ou de segurança, sem que isso implique a ausência de motivações solidárias.

Por exemplo, a Colômbia concentra suas 
ações de CSS em países limítrofes e na região do Caribe. A Venezuela divide sua atenção com esses últimos, com Cuba como principal sócio, e América Central, com uma presença menor na América do sul, onde prioriza seus aliados políticos (Bolívia e Equador). A Argentina se centra no âmbito sulamericano e mais especificamente em seus vizinhos e sócios do MERCOSUL (Bolívia e Paraguai). Enquanto o México aumenta sua presença, sobretudo, na América Central e Caribe. O Brasil é o único país da região que mostra maior diversificação em sua cooperação, dirigindo-se prioritariamente à América Latina, com El Salvador na América Central, Bolívia na América do Sul e Haiti e Cuba no Caribe como principais destinatários. Isso sem descuidar sua presença crescente na África, de modo destacado em projetos de cooperação nos países de língua portuguesa, como sócios prioritários e, em menor medida, na Ásia, no Timor Oriental.

O último informe publicado pela Secretaria Geral Ibero-americana (SEGIB, 2011), que dá conta do estado da CSS na região, registra, em 2010, um total de 529 projetos e 313 ações de cooperação horizontal Sul-Sul bilateral, com um predomínio de infraestrutura e serviços econômicos e produtivos (33,2\% em projetos e 30,2\% em ações), dos setores sociais ( $28 \%$ em projetos e $45 \%$ em ações) e de outras dimensões, como meio ambiente, gênero, governo e cultura (38,7\% em projetos e $24,3 \%$ em ações).

A gestão de interdependências ocupa um lugar destacado na agenda da CSS regional, com ações de desenvolvimento fronteiriço, local e territorial, cooperação policial e judicial, bens públicos ou prevenção e redução de desastres naturais. Além disso, foi incorporada ao espectro da CSS a criação de mecanismos para a correção e redução de assimetrias, como o Fundo de Convergência Estrutural do MERCOSUL (FOCEM), que financia projetos de infraestrutura, habitação, saneamento básico e turismo, principalmente nos países menores do bloco (Uruguai e Paraguai).

Não devemos esquecer que a CSS se integra nas políticas exteriores latino-americanas e é funcional para as diferentes estratégias nacionais orientadas a fortalecer uma presença positiva no

mundo, essencialmente em outros países da região (Colacrai, 2011). Essas estratégias se apresentam claramente através das diferentes visões da CSS, que alimentam as políticas de cooperação de Venezuela, Brasil e Colômbia, três países que, com diferentes perfis políticos, buscam exercer certa liderança na CSS que tem lugar na América Latina. A Venezuela baseia sua liderança entre os países centro-americanos e caribenhos na riqueza gerada pelo petróleo e no modelo alternativo do socialismo bolivariano, que instrumentaliza a cooperação para apoiar governos ideologicamente afins e propugna um rompimento com os cânones tradicionais da cooperação Norte-Sul. A Colômbia aposta num alinhamento da CSS com os países do CAD/OCDE, adotando diretrizes dos doadores tradicionais em matéria de eficácia, convertendose em seu maior difusor na região. O Brasil sustenta sua cooperação no papel de líder regional com aspirações globais e no nível de desenvolvimento de sua indústria e alguns setores de ponta (agricultura, energia, saúde) o que coloca o gigante sul-americano em uma posição central na CSS latino-americana.

Não estaria completo o panorama da CSS sem mencionar sua importância nos processos de integração e regionalização (Ojeda, 2010). Essa variante da CSS se evidencia no marco de estratégias regionalistas de caráter pós-liberal que pretendem reformular e reorientar os rumos integracionistas na América Latina (ALBA - Tratado Comercial dos Povos MERCOSUL, UNASUL), gerando espaços de cooperação mais políticos que no passado. Predominam, nesses processos, as visões mais desenvolvidas do papel do Estado, um maior grau de participação e preocupação com as dimensões sociais e, em alguns casos, a criação de instituições e de políticas comuns. Estamos diante de uma reinterpretação do regionalismo e da integração que aposta numa agenda positiva e numa cooperação fortalecida, para além de sua dimensão comercial, com mecanismos da CSS de diálogo e de acordo político, e instituições para a defesa da democracia, da paz e da segurança regional (Sanahuja, 2010).

Definitivamente, a CSS, na América Latina, 
tanto na sua dimensão bilateral como regional, apresenta claras funcionalidades, ao gerar, para além da retórica política, solidariedades de fato e fortes conexões entre as esferas administrativas, sociais e técnicas das instituições e organizações nacionais envolvidas. Hoje, a CSS é um fator de coesão política regional e de organização da agenda latino-americana de desenvolvimento em torno de setores e temas comuns, onde os organismos financeiros multilaterais ou doadores já não têm a batuta. Nesse sentido, a CSS une e não separa, aglutina e não desagrega, o que não é um dado menor na história da região.

A CSS na ALC se apresenta hoje como uma realidade heterogênea e caleidoscópica. Se bem que haja denominadores comuns mínimos, em torno de seus princípios básicos e sua filosofia, bem como uma vontade política firmemente assentada em oferecê-la e recebê-la, nem todos os países a realizam da mesma forma, nem com a mesma amplitude, intensidade, escala e grau de diversificação quanto aos âmbitos setoriais compartilhados, o que dá mostras do grau diverso de desenvolvimento na realidade latino-americana e das capacidades díspares para estruturar a CSS e fazê-la efetiva, para além da retórica. Em resumo, identificamse, na América Latina, países que propõem um modelo de cooperação mais semelhante aos dos países do CDA/OCDE, rechaçando qualquer apoio externo, e os que defendem modelos mais pragmáticos e autônomos, propensos ao trabalho conjunto com sócios externos através da cooperação triangular e dispostos a dialogar sem renunciar a suas próprias visões no que se refere à eficácia da ajuda.

A UE deveria saber interpretar essas mudanças, oferecendo uma resposta cooperativa à altura das circunstâncias. Não se trata apenas de uma necessidade de caráter moral ou de um interesse político em compartilhar valores ou identidade cultural com os sócios latino-americanos. Estamos falando da importância de a UE entender as mudanças nesses países e reagir rápido, para não perder espaço na sociedade latino-americana, para continuar exercendo influência geopolítica frente ao rápido avanço de atores extrarregionais e, por que não dizer, para não ceder importantes cotas de mercado em uma região que cresce economicamente, possui matérias-primas de todo tipo e vê ampliada diariamente sua base de negócios pela incorporação paulatina dos setores sociais mais humildes aos circuitos de consumo e de crédito. Os dados nos informam sobre um retrocesso europeu e um declive geopolítico e geoeconômico na região na última década. A UE não aproveitou oportunidades claras. Se, em 1990, a Europa era responsável por 25\% do comércio na América Latina, hoje esse percentual ronda se aproxima de $14 \%$. Os investimentos estrangeiros diretos também diminuíram (Gratius, 2011, p.91)

No que diz respeito à cooperação, a retirada de doadores europeus, ou a redução de fundos e uma maior seletividade têm sido a tônica nos últimos anos. Alguns fecharam seus escritórios, outros diminuíram sua AOD, em um movimento que foi seguido por outros doadores e que levou a região a passar para um segundo plano como receptora de ajuda. Salvo no caso da Espanha que, em média, definiu $46 \%$ de sua ajuda bilateral à região, para outros países europeus, a América Latina não é uma área prioritária. Para a Alemanha e a Holanda, representa $11 \%$ de sua ajuda mundial, para a França, 5\%, e para o Reino Unido, 2\%, enquanto a CE dirigiu, no mesmo período, $10 \%$ de sua AOD para a região (DAC; OCDE, 2012).

Os dados sobre o volume da ajuda internacional dos membros do DAC/OCDE nos dizem que os recursos públicos orientados para o desenvolvimento dos países latino-americanos foram estancados no século XXI, mostrando uma clara tendência à redução, em um contexto de incrementos na AOD destinados aos países mais pobres, como consequência da agenda dos ODM e dos compromissos assumidos pelo G-8 para o perdão da dívida da África, a partir de 2005. Se, nos anos 90, as contribuições oficiais para o desenvolvimento da América Latina representavam 13\% do total da AOD mundial, no século XXI, essa cota se situa em torno de 7\%. Se, em 1990, a AOD recebida era de $0,54 \%$ do PIB regional, em 2007 era apenas de $0,22 \%$ da riqueza gerada pelos países latino-ame- 
ricanos. Não é alheio a essa realidade o fato de a região ser uma das mais avançadas no cumprimento dos ODM e que existam grandes possibilidades de alcançar 17 das 18 metas fixadas.

Pelo lado da demanda, os países latinoamericanos atribuem menos importância à cooperação tradicional. Diante do incremento da CSS e do crescimento econômico dos países latinoamericanos, a cada dia a cooperação europeia é menos relevante em termos quantitativos, ou quando é comparada a outros fluxos externos (divisas de turismo, remessas, comércio, etc.). Em 2008, a AOD mundial na América Latina ascendia a 8.700 milhões de dólares, enquanto as remessas representavam 8 vezes mais (63.000 milhões) e os investimentos estrangeiros diretos, 16 vezes mais (127.000 milhões).

Contudo, nem a UE nem seus Estados Membros contam ainda com uma visão de conjunto, nem com uma clara definição estratégica que permita estruturar e desenvolver, com impulso suficiente, uma política de apoio e de resposta à CSS, não só na América Latina como também em suas relações com outros países em desenvolvimento e potências emergentes. Com efeito, uma revisão das principais normas comunitárias nos mostra que nem o Tratado de Lisboa nem o Tratado de Funcionamento da UE possuem referências diretas à CSS ou à cooperação triangular como modalidades ou instrumentos aos quais a cooperação comunitária para o desenvolvimento deva dedicar atenção. Foi, no marco das relações entre a UE e a América Latina, que o Parlamento Europeu (PE) contemplou a conveniência de prestar mais atenção à CSS. Também o fez a Comunicação da CE intitulada "Uma associação reforçada entre a União Europeia e a América Latina”, de 8 de dezembro de 2005, em cuja comunicação se constatava a envergadura da mobilização dos "países em projetos de solidariedade e cooperação Sul-Sul”, destacando "a necessidade de ampliar a cooperação com aqueles países latino-americanos que não só lutaram com êxito em suas próprias sociedades para avançar na realização dos ODM, mas que, além disso, estão protagonizando uma notabilíssima mobilização de solidariedade e cooperação Sul-Sul. ${ }^{3}$

Quanto ao Conselho, é no contexto das reuniões de cúpula birregionais entre a UE e os países da América Latina e Caribe, iniciadas em 1999, e no processo de construção de uma associação estratégica, onde encontramos referências à CSS. De concreto, na sexta Reunião de Cúpula, realizada em Madri, em maio de 2010, a CSS e a relação triangular aparecem refletidas no ponto $37 \mathrm{da}$ Declaração final, mencionadas como principais objetivos do Plano de Ação Conjunto 2010-2012. Um pouco antes, no mês de março, no $1^{\circ}$ semestre de 2010, durante a presidência espanhola da UE, o Conselho elaborou algumas contribuições ao Evento de Alto Nível sobre CSS e Desenvolvimento de Capacidades realizado em Bogotá. Trata-se do único documento da UE onde se esboçam articuladamente argumentos a favor do apoio à CSS triangular. Destaca-se a necessidade de contar com definições claras e marcos conceituais precisos sobre essas formas de cooperação, que propiciem uma melhor compreensão de suas características. O Conselho deu as boas vindas a esse tipo de cooperação e estimulou a geração de evidências sobre sua eficácia para construir uma ponte entre a CSS e a Norte-Sul.

Por sua vez, a Comissão introduziu paulatinamente a CSS em sua agenda de cooperação global. Dois documentos fazem menções muito breves à CSS e ao papel dos novos doadores, em ambos os casos relacionados com o financiamento do desenvolvimento. No primeiro, o Livro Verde do crescimento inclusivo e desenvolvimento sustentável, a Comissão recorda que, apesar do crescimento da CSS, do financiamento público nos países em desenvolvimento e da AOD, as necessidades de recursos para cumprir com os ODM são maiores. ${ }^{4}$ No segundo, na comunicação "Plano de Ação da UE em doze pontos em apoio dos ODM",

${ }^{3}$ Resolução do Parlamento Europeu sobe uma Associação reforcada entre a União Europeia e a América latina (2005, p.2241 (INI). Comunicação de José Ignacio Salafranca, 07 abr. 2006 .

${ }^{4}$ EU development policy in support of inclusive growth and sustainable development - Increasing the impact of EU development policy”.COM (2010) 629 final. Brussels, 10.11.2010. 
faz-se um chamamento para que todos os doadores, inclusive os novos, se comprometam numa distribuição equitativa de encargos para equiparar seu grau de ambição com o da UE. Nesse contexto, são reconhecidas as contribuições dos novos doadores e da CSS para completar as necessidades de financiamento do desenvolvimento. ${ }^{5}$

No que diz respeito à política de cooperação da UE para a América Latina, também se identifica a presença da CSS na comunicação da Comissão intitulada "A UE e AL: uma associação de atores globais" (2009), onde se encontra uma menção que abre a porta ao apoio à CSS e triangular. Assinala-se que "os países da região adotaram uma política de cooperação com os países mais pobres”, razão pela qual devem ser exploradas "outras oportunidades de CSS e triangular" e se propõe o desencadeamento de uma cooperação triangular com sócios latino-americanos e de outras regiões, com a finalidade de contribuir para os ODM e enfrentar ameaças transregionais.

Finalmente, no marco das Parcerias Estratégicas firmadas respectivamente com o Brasil (2007) e o México (2008), a promoção da CSS se beneficia de uma vontade política muito mais assumida que nos acordos birregionais. No que diz respeito ao Brasil, a Comunicação da Comissão "Para uma associação estratégica UE-Brasil”“ inicia o parágrafo dedicado ao cumprimento dos ODM e ao fomento do desenvolvimento regional com um reconhecimento do programa brasileiro de cooperação:

Igualmente a outras novas potências, o Brasil participa cada vez com mais energia da CSS, especialmente em sua própria vizinhança e na África lusófona. Enquanto o compromisso da maior parte dos "novos doadores" aspira, frequentemente, à geração de resultados e créditos em curto prazo, a ênfase do programa de cooperação do Brasil (de proporções relativamente reduzidas) tende mais para um desenvolvimento em longo prazo e sustentável. O Brasil é conhecido por sua ativa defesa do multilateralismo e a favor do desenvolvimento de modelos inovadores de cooperação multilateral e trilateral [...]. As proposições da UE e DO Brasil convergem no que se refere à cooperação para o desenvolvimento como meio de fomentar a paz e a segurança.

${ }^{5}$ COM (2010) 159 final. Bruxelas, 21.4.2010

${ }^{6}$ COM (2007) 281 final. Bruxelas, 30.5.2007.
Nesse documento, identifica-se a preferência da Comissão por "explorar vias para a cooperação triangular com o Brasil e a Comunidade de Países de Língua Portuguesa (CPLP) em matéria de energia" e estabelecer um marco "para consolidar as relações com o Brasil e os países africanos lusófonos". No âmbito caribenho, propõe-se a cooperação e a coordenação dos esforços brasileiros e da UE no Haiti, no marco das operações de paz e estabilização. No âmbito dos países sul-americanos, sugere-se o apoio da UE à disseminação da experiência brasileira entre seus vizinhos, no que se refere a soluções inovadoras aplicadas na luta contra a pobreza, a desigualdade, a exclusão social, a redução dos desequilíbrios regionais, a proteção social e o trabalho digno.

Essas sucintas referências foram ampliadas no Plano de Ação conjunta firmado na II Reunião de Cúpula UE-Brasil do Rio de Janeiro (2008). Nesse documento, reitera-se o papel da cooperação triangular como instrumento idôneo para consolidar a paz, proporcionar assistência a países em situação pós-conflito e lutar contra a criminalidade. Ampliaram-se os potenciais setores de atuação conjunta, incluindo os direitos humanos, a construção da paz e a assistência pós-conflito no Haiti e na Guiné Bissau. O Plano inclui uma seção sobre "diálogo bilateral em desenvolvimento global e cooperação em terceiros países", onde se afirma que "o Brasil e a UE estão convencidos de que, unindo forças, podem acelerar o progresso em direção a essas prioridades compartilhadas", atribuindo grande importância "ao papel da cooperação triangular", que deve ser uma das principais prioridades da associação estratégica.

O último plano de Ação Conjunta BrasilUE (2012-2014) multiplica as referências à cooperação triangular, considerando-a uma das "principais áreas da associação estratégica, de grande importância para acelerar o progresso em direção às prioridades compartilhadas". Segundo o texto, a cooperação triangular "deve respeitar princípios tais como a apropriação pelo país sócio e a adequação a suas estratégias de desenvolvimento e considerar a dimensão cultural." 


\section{MUDANÇAS NA POLÍTICA DE COOPERAÇÃO DA UE (2014-2020)}

A UE se encontra na fase final de árduas negociações sobre as perspectivas financeiras que definirão o orçamento comunitário entre 2014 e 2020 e estabelecerão os recursos que o bloco dedicará à cooperação para o desenvolvimento, um dos indícios de identidade como "potência civil solidária”. Em um contexto de crise econômica e intranquilidade política que ameaça o projeto europeu, alargando sua sombra sobre a desintegração da UE, os Estados Membros e as instituições comunitárias estão redefinindo sua política de cooperação para a América Latina, adaptando seus instrumentos às novas circunstâncias e modulando o tipo de cooperação que oferecerão a uma região onde praticamente a totalidade de seus países estão sob o rótulo de "renda média".

Com efeito, nenhum dos países latino-americanos e caribenhos, salvo o Haiti, se encontra, neste momento, no grupo dos Países Menos Desenvolvidos (Least Developed Countries) ou de Países de Renda Baixa, como um grupo de cinquenta países e territórios majoritariamente africanos e asiáticos, caracterizados por apresentar os piores índices de desenvolvimento socioeconômico e renda per capita inferior a 1.000 dólares por ano. A América Latina é uma região conformada, se- gundo esses critérios, como PRM. Dentre esses, em sua maioria, os países latino-americanos são agrupados segundo as listas de receptores de AOD elaborada pelo CAD/OAD na subcategoria de Países de Renda Média Alta, com uma renda per capita compreendida entre 3.976 e 12.275 dólares por ano. Pertencem a esse grupo Argentina, Brasil, Chile, Colômbia, Costa Rica, República Dominicana, Equador, México, Panamá, Peru, Uruguai e Venezuela. Na subcategoria de Países de Renda Média Baixa, encontram-se o resto dos países latino-americanos com renda per capita anual entre 1.006 e 3.975 dólares, isto é, Bolívia, El Salvador, Guatemala, Guiana, Honduras, Nicarágua e Paraguai.

Entretanto, seria uma visão estreita pensar exclusivamente na renda per capita como justifi- cativa do apoio aos países latino-americanos em sua luta contra a pobreza. Existem outros argumentos que ganham cada dia mais peso, vinculados à crescente importância da CSS em uma região que busca outro tipo de cooperação, pois está obtendo êxito na luta contra a pobreza e no crescimento econômico, mas na qual persistem problemas como a desigualdade, a insegurança e a falta de equidade no acesso à renda e em outros campos, como o acesso à justiça, a educação, a propriedade da terra ou o emprego, especialmente em grupos étnicos, jovens e mulheres. A América Latina avança no caminho do desenvolvimento, mas necessita consolidar essas conquistas e superar os déficits estruturais, as carências institucionais e os desafios sociais para os que continuam necessitando de cooperação, talvez de outras formas e com outros instrumentos, mas, ao fim e ao cabo, de cooperação. Abandoná-la num processo "desordenado" de retirada de doadores seria uma péssima mensagem e um desestímulo para o desenvolvimento de outras regiões do mundo, já que não se devem penalizar os êxitos na luta contra a pobreza com o corte abrupto da ajuda.

Frente a essas circunstâncias, a UE intenta responder cooperativamente aos desafios da CSS e dos países emergentes, especialmente latino-americanos, definindo novas formas de trabalho e adaptando sua cooperação às mudanças em seu nível de desenvolvimento. Um passo importante foi a negociação das perspectivas financeiras da UE com a apresentação de novos instrumentos de cooperação para o desenvolvimento adaptados à realidade de um mundo com potências emergentes e que responde à imperiosa necessidade de modular, de forma diferenciada, a cooperação comunitária, construindo uma perspectiva sobre os emergentes e as melhores formas de cooperar com eles Nesse sentido, a comunicação da CE de 13 de outubro de 2011, intitulada "Incremento do Impacto da política de desenvolvimento da UE: Programa para a mudança”, anuncia uma reorientação da cooperação comunitária, que se estende às propostas sobre os instrumentos de ação exterior nos quais se concretiza. A modificação do 
Instrumento de Cooperação para o Desenvolvimento (ICD, onde estavam incluídos os países latinoamericanos) e a substituição do instrumento anterior de Cooperação com países Industrializados por um novo "Instrumento de Partenariado" (IP) para a cooperação com terceiros países recolocaram os países maiores da América Latina junto aos emergentes. Se bem que seja certo que essa proposta representa um avanço, trata-se ainda de um enfoque fragmentado e com dificuldades para articular formas de trabalho conjunto, com formatos inclusivos e horizontais como os que propiciaram um comprometimento da UE mais orientado para o desenvolvimento e a construção de associações inovadoras e menos para a defesa de seus interesses econômicos e estratégicos, como pode ser deduzido de uma leitura atenta do IP.

No “Programa para a Mudança”, afirma-se a necessidade de um enfoque diferenciado na política de desenvolvimento da UE que considere as crescentes divergências entre países em desenvolvimento, dado que vários países sócios passaram a ser "doadores" e que as dificuldades econômicas e orçamentárias tornam mais crítico garantir o emprego eficaz e com mais resultados da ajuda, maximizando seu potencial de mobilização de outras fontes de financiamento. Para os países em desenvolvimento mais avançados, com capacidade de gerar recursos próprios suficientes, afirmase que "a ajuda à base de subvenções não deveria figurar na cooperação geográfica" e que o espectro de situações enfrentadas pelos países em desenvolvimento recomenda "um enfoque diferenciado na concessão de ajudas”.

Os critérios para estabelecer o tipo de instrumento (o IC ou o IP basicamente) que regerá a cooperação com a CE são as necessidades do paíssócio, as capacidades, os compromissos e seus resultados e o impacto potencial da UE avaliados através dos objetivos horizontais: por um lado, o grau em que a cooperação comunitária poderia fomentar e apoiar reformas políticas, econômicas, sociais e relativas ao meio ambiente nos países associados e, por outro, o efeito multiplicador da ajuda da UE sobre outras fontes de financiamento do desenvolvimento, em particular o investimento privado. ACSS menciona, explicitamente uma vez, no que se refere ao apoio, que a UE o dispensará aos processos de integração regional, "incluídas as iniciativas Sul-Sul, em âmbitos como infraestrutura, mercados, cooperação transfronteiriça, déficit de competitividade, ajuda ao comércio e acordos de associação econômica e de livre comercio.”

Quanto aos instrumentos que entrarão em vigor em 1 de janeiro de 2014, justifica-se a exclusão dos Países de Renda Média Alta (e alguns de renda média baixa, de acordo com o tamanho do PIB, como Índia e Indonésia) do Instrumento de Cooperação para o Desenvolvimento, no que se refere à cooperação bilateral (não na regional, onde continuam incluídos) e sua consideração no novo IP, como "consequência de haverem empreendido um caminho exitoso de desenvolvimento sustentável ou de terem obtido bons resultados no acesso a recursos externos de financiamento". Para esses, reconhecidos com um novo e crescente papel regional e global, a UE adaptará a natureza de suas relações incluindo outras prioridades, o que não deve significar o enfraquecimento das relações, mas sim a adoção de um moderno conjunto de instrumentos, como os "novos partenariados" sobre a base de programas regionais e temáticos (sob o ICD) ou de instrumentos financeiros da ação exterior da UE, mas não necessariamente vinculados ao desenvolvimento dos países-sócios.

Dessa maneira, fica fora da cooperação bilateral do ICD um total de 19 países: Argentina, Brasil, Chile, Colômbia, Costa Rica, Equador, México, Panamá, Peru, Uruguai e Venezuela, na América Latina, e China, Irã, Malásia, Maldivas, Tailândia, Kazajistão, Índia e Indonésia, no resto do mundo. Em seu artigo 3.9, o regulamento do ICD contempla explicitamente o apoio da UE aos países cobertos pelo instrumento, através, entre outras modalidades, da cooperação triangular. O ICD tem uma dotação de 23.295 milhões de euros, quase $25 \%$ do orçamento para o período de 20142020 (96.249 milhões de euros).

No que diz respeito ao "Instrumento de Partenariado para a Cooperação com Países 
Industrilizados", a proposta da Comissão considera esse instrumento como uma "ferramenta-chave de política exterior”, com base no princípio de "diferenciação" para os PRM e emergentes, como Brasil, China ou Índia, entre um total de dezessete sócios, com os quais se pretende "promover os interesses da UE através do apoio à dimensão exterior de políticas internas (segurança energética, mudança climática e meio ambiente)", utilizando, de acordo com os casos, a cooperação triangular para reduzir a pobreza em países menos exitosos.

O IP não é tanto um mecanismo de oferecimento de AOD (salvo nos rótulos de ajuda para comércio e assistência relacionada ao comércio), como uma resposta à cooperação com as novas economias existentes em temas vinculados estritamente aos interesses da UE e aos desafios comuns enfrentados. Busca agendas que vão mais além da cooperação para o desenvolvimento com esses países emergentes e busca - como se afirma precisamente no texto - "facilitar o acesso a mercados e desenvolver o comércio, os investimentos e as oportunidades de negócio para as companhias europeias [...] e incrementar a compreensão e a visibilidade da UE e seu papel na cena mundial através da diplomacia pública, a cooperação educativa e acadêmica e outras atividades que promovam os valores e interesses da UE”. Pretende também ser um instrumento para honrar os comamericanos) e o impulso para processos de integração regional. Ao contrário, de maneira com- plementar, poder-se-ia incorporar o apoio à CSS como uma terceira dimensão, em consonância com a transformação que os países latino-americanos experimentaram na última década.

\section{CONCLUSÕES: a imperiosa necessidade de adaptar-se}

Definitivamente, as mudanças na distribuição do poder e na geração da riqueza mundial colocam sérios e urgentes desafios para a UE. O vigor das relações Sul-Sul, o fortalecimento de espaços autônomos para acordos e cooperação política entre países em desenvolvimento e a crescente presença de outros atores na África e na América Latina são transformações de desafiam a UE a redefinir suas estratégias e instrumentos para continuar sendo um ator relevante na promoção do desenvolvimento.

A UE deveria incorporar, em suas estratégias e em seus instrumentos de cooperação com a América Latina, mecanismos horizontais baseados no enfoque do intercâmbio de conhecimentos, na difusão de experiências exitosas e na exploração de fórmulas complementares de cooperação com capacidade de potencializar as respectivas forças, europeias e latino-americanas. Importa que a UE e seus Estados Membros definam uma estratégia comum e coordenada ante a realidade de um mundo em desenvolvimento mais autônomo, mais afirmativo e que diversifica suas opções de inserção internacional.

Não obstante, a UE procederá com cautela diante do avanço da CSS, não tanto quanto a seus princípios, filosofia e contribuições ao desenvolvimento, senão na medida em que a coexistência de diferentes formas de colocá-la em prática recomenda ponderar sobre a conveniência de um enfoque seletivo. Qualquer decisão deve ser tomada a partir de evidências mais claras e de um conhecimento detalhado das modalidades que possuem um maior potencial desenvolvimentista. Tampouco se devem menosprezar suas implicações no diálogo de políticas ou nos aspectos 
normativos que a CSS sempre incorpora e nos impactos para o reforço da coordenação e harmonização entre os doadores.

Não há dúvida de que a crise afetará a cooperação nos próximos anos. Isso já está acontecendo nos países que mais sofrem seus efeitos. $\mathrm{O}$ governo socialista da Espanha, um dos principais doadores regionais, cortou 1.200 milhões de euros do orçamento da AOD entre aos anos de 2010 e 2011. Seu sucessor, o governo do Partido Popular, aprofundou essa tendência, ao anunciar, em 13 de março de 2012, reduções adicionais de 1.389 milhões de euros. Em outros países, às tendências restritivas de financiamento de sua cooperação se unem a seletividade e a reorientação dos programas, ao calor de acontecimentos como a "primavera árabe”, que fazem ressurgir temores sobre avalanches migratórias, estrangulamentos energéticos e novas demandas de intervenção para estabilizar a região e responder a crises humanitárias.

Por outro lado, o modelo de prosperidade que a UE intentou difundir através de sua cooperação tem hoje outras alternativas, pois é evidente a quebra do pensamento único e das práticas padronizadas, do tipo on size fits all, no debate sobre o desenvolvimento. A "ascensão do resto" rótulo original de Fareed Zakaria para assinalar a chegada dos países emergentes como uma das três mudanças tectônicas do poder nos últimos quinhentos anos - modificou os termos da equação da economia, da política e o desenvolvimento sustentável. Já não é possível decifrar as incógnitas do sistema internacional sem contemplar uma miríade de siglas (BRICS, IBAS, BIC, EAGLES, CIVETS, PRM, BRICSAM, etc.) que refletem mudanças estruturais na criação da riqueza e na distribuição do poder.

No âmbito da cooperação para o desenvolvimento, os emergentes continuam aumentando e consolidando sua oferta cooperativa, compartilhando suas experiências de êxito e seus avanços na luta contra a exclusão social junto a outros países em condições similares. Essa realidade da CSS e suas diferenças com respeito à cooperação "tradicional” já são reconhecidas unanimemente como manifestação da existência de outros modelos e alternativas de cooperação que refletem as mudanças na geopolítica mundial e na geografia do crescimento econômico que se desloca, com passos agigantados, do Norte ao Sul, do Ocidente ao Oriente.

O último marco desse reconhecimento foi produzido na Declaração Final do $4^{\circ}$ Fórum de Alto nível sobre Eficácia da Ajuda (Coreia do Sul, dezembro de 2011), que destacou as diferenças da "natureza, as modalidades e as responsabilidades" da CSS com respeito às aplicadas à Cooperação Norte-Sul, as perspectivas alentadoras que a pluralidade de enfoques oferece, na prática da cooperação, os recursos adicionais que aporta e o enriquecimento das aprendizagens que incorpora.

Esperemos que as instituições comunitárias, os Estados Membros e as potências emergentes possam responder ao desafio de um mundo em transformação acelerada, no qual a horizontalidade e a construção de associações através da CSS não sejam apenas meras opções, mas constituam imperativos de nossa época. Assim se expressou, de forma brilhante, a presidente Dilma Roussef, no discurso de abertura da $66^{\mathrm{a}}$ Assembleia Geral das Nações Unidas: “Um novo tipo de cooperação, entre países emergentes e desenvolvidos. É a oportunidade histórica para redefinir, de forma solidária e responsável, os compromissos que regem as relações internacionais". ${ }^{7}$

(Recebido para publicação em 30 de março de 2012) (Aceito em 25 de julho de 2012)

\section{REFERÊNCIAS}

BARBÉ, E. Multilateralismo: adaptación a un mundo con potencias emergentes. Revista Española de Derecho Internacional, Madri, v.62, n.2, p.21-50, 2010.

BIATO, M. La apuesta de Brasil por el comercio Sur - Sur. Economía Exterior, Madri, n.52, primavera, p.29-38, 2010.

COLACRAI, M. Escenarios y desafíos de la cooperación Sur-Sur a 30 años de la Declaración de Buenos Aires. Documento de Trabajo, Buenos Aires, CICI + D,

${ }^{7}$ Discurso da Presidente Dilma Rousseff na abertura do debate geral da $66^{\mathrm{a}}$ Assembleia Geral das Nações Unidas, New York, 21 de setembro de 2011. 
Universidad Nacional de San Martín, Dirección General de Cooperación Internacional, n.1, 2011.

DAC. Development Assistance Committee; OCDE Organization for Economic Cooperation and Development. Development aid at glance statistics by region (Africa, America, Asia, Europe and Oceania). Paris: 2012 .

DESA. Department of Economic and Social Affairs; ONU. Development cooperation for the $M D G^{\prime}$ 's: maximizing results. New York: 2010.

ECOSOC. Economic and Social Council; ONU. Background study for the Development Cooperation Forum Trends in South-South and triangular development cooperation. New York: april, 2008.

GHSi. GLOBAL HEALTH STRATEGIES inititatives. Shifting paradigm. How the BRICS are reshaping global health and development. 2012. Disponivel em www.ghsinitiatives.org/downloads/ghsi_brics_report.pd

GRATIUS, S. El ascenso de América Latina. In: MARTINIGUI, A.; YOUNGS, R. Desafíos para la política exterior europea en 2012. Madrid: FRIDE, 2011. p. 85-91

GRIMM, S.; HUMPHREY, J.; LUNDSGAARDE, E.; DE SOUZA, S. European development cooperation to 2020 challenges by new actors in international development EDC 2020. Working Paper, London, n.4, 2009.

IPEA; ABC. Agencia Brasileira de Cooperação. Cooperacão brasileira para o desenvolvimento internacional: 20052009. Brasília, 2010.

IPEA. Objetivos de desenvolvimento do milênio: relatório nacional de acompanhamento. Brasília: SPI/MP, mar. 2010

KADAH, M.M. The G-20 and the power club approach to global gobernance: the price of efficiency. IPRIS Viewpoints. Lisboa: mar. 2012.

KERN, A.; WEISTAUBB, L. El debate sobre la Cooperación Sur - Sur y su lugar en la política exterior argentina. Revista Española de Desarrollo y Cooperación, Madri, Universidad Complutense de Madrid, n.27, p.83- 95, 2011.

MELLO e SOUZA, A. A cooperacão para o desenvolvimento Sul - Sul: os casos do Brasil, da India e da China. Boletim de Economia e Política Internacional, Brasilia, IPEA, n.9, p.89- 100, jan./mar. 2012.

MILANI, C. Les pays émergents dans l'actuel ordre mun-

1. Changements et legitimite politique Revue
MRE. Ministerio das Relaçoes Externas. Emerging tructures of global governance. Brasilia: 2010.

NACIONES UNIDAS. Estado de la Cooperación Sur Sur. Informe del Secretario General. Asamblea General. A the future of the power /66/229. New York: ago. 2011.

NYE, Joseph. The future of power. Washington DC.: PublicAffairs. 2010. 320p.

OCDE. Organização para Cooperação e Desenvolvimento Econômico. Perspectives on global development 2010. Paris: Shifting Wealth, 2010.

OJEDA, T. La cooperación Sur-Sur y la regionalización en América Latina: el despertar de un gigante dormido. Relaciones internacionales.Madri: GERI; Universidad Autónoma de Madrid, p.91-111, 2010.

POSTEL-VINAY, K. Le G-20, laboratoire d'un monde émergent. Paris: Presses de Sciencies Po., 2011. 174p.

SANAHUJA, J.A. Suramérica y el regionalismo posliberal. In: _ ; CIENFUEGOS, M.; (Coord.). Una región en construcción: UNASUR y la integración en América del Sur. Barcelona: Fundació CIDOB, p.87-134, 2010.

SANTANDER, G. La cooperación Sur - Sur: experiencias de interés e implicaciones para el sistema internacional de ayuda. Sistema, New York, n.220, p.59-78, 2010.

SEGIB. Secretaría General Iberoamericana. Informe de la cooperación Sur-Sur en Iberoamérica 2010. Estudios SEGIB, Madrid, n.5, 2011.

SCHULZ, N. La UE: ¿Un socio que no quiere crecer. Policy Brief, Roma, FRIDE, n.33, feb. 2010

SIDIROPOULOS, E. India and South Africa as partners for development in Africa? Chatam house, briefing paper. London: mar., 2011.

WALTZ, J.;. RAMACHANDRAN, V. A Literature review of emerging donors and the changing nature of foreign assistance. Working Paper, [S.1.], Center for Global Development, n.273, nov. 2011.

ZIMMERMANN, F; SMITH, K. More actors, more money, more ideas for international development co-operation. Journal of International Development, Wiley Online Library, n.23, p.722-738, 2011. 


\section{GLOBA TRANSFORMATIONS, EMERGING POTENCIES AND THE SOUTH-SOUTH COOPERATIONS: challenges for the European cooperation}

\section{Bruno Ayllón Pino}

The European Union (EU) and its Member States face the challenge of adapting its policy of cooperation for the development to a world stressed by swift changes in the creation and distribution of wealth and in the diffusion of power. The rise of the emerging countries, the peak of the South-South Cooperation (SSC), the advances in the fight against poverty in countries with an average income, or the traumatic impact of the crisis on the countries of the Organization for Economic Cooperation and Development (OCDE) are factors that give origin to major structural transformation and demand a modification of the sense and practice of European cooperation. The negotiation of financial perspectives for 2014-2020 and the renovation of the instruments of cooperation of the European Commission (CE) are a first answer to these changes. The major concerns demonstrated by SSC in some of the member states, as well as the initiatives of triangular cooperation triggered in countries like Brazil are a sign of search of horizontality and complementarity in the European cooperation with Latin-American countries.

KEY WORDS: emerging countries, South-South cooperation, cooperation instruments, triangular cooperation, EU-Brazil strategic association.

\section{TRANSFORMATIONS MONDIALES, PUISSANCES EMERGENTES ET COOPERATION SUD-SUD: les défis de la coopération europénne}

\author{
Bruno Ayllón Pino
}

L'Union Européenne (UE) et ses États Membres sont confrontés au défi d'adapter leur politique de coopération pour le développement à un monde marqué par des changements rapides quant à la création et à la distribution des richesses ainsi qu'à la diffusion du pouvoir. La montée des pays émergents, l'apogée de la Coopération SudSud (CSS), les progrès réalisés au niveau de la lutte contre la pauvreté dans les pays de Revenus Moyens (PRM), ou l'impact traumatisant de la crise dans les pays de l'Organisation pour la Coopération et le Développement Économique (OCDE), sont des facteurs à la base de grandes transformations structurales et ont imposé un changement de sens et de pratique de la coopération européenne. La négociation des perspectives financières pour 2014-2020 et la réforme des instruments de coopération de la Commission Européenne (CE) constituent une première réponse à ces changements. Lintérêt majeur de la CSS dans certains Etats Membres et le déclenchement d'initiatives de coopération triangulaire avec des pays comme le Brésil sont signes d'une recherche d'horizontalitéet de complémentarité de la coopération européenne avec les pays d'Amérique Latine.

MoTS-CLÉS: pays émergents, coopération Sud-Sud, instruments de coopération, coopération triangulaire, Association stratégique UE-Brésil.

Bruno Ayllón Pino - Doutor em Relações Internacionais. Pesquisador e professor associado ao Instituto Universitario de Desenvolvimento e Cooperação da Universidade Complutense de Madri, Espanha. Pesquisador com bolsa do PNPD (Instituto de Pesquisa Econômica Aplicada, IPEA) no projeto Cooperação Internacional ao Desenvolvimento. Pesquisador associado ao Núcleo de Pesquisa em Relações Internacionais da USP. Professor visitante em Universidades argentinas e brasileiras. Professor do Mestrado em Relações Internacionais da Universidade del Salvador, Buenos Aires, Argentina. Tem experiência e trabalha como professor, pesquisador e consultor na área de Ciência Política, Relações Internacionais, Cooperação Internacional para o Desenvolvimento, Cooperação Sul-Sul, Relações Brasil Espanha, Relações União Européia - America Latina, Processos de Integração na América do Sul (MERCOSUL), Teoria das Relações Internacionais e Sistema Político Brasileiro. Publicações recentes: As contribuições do Brasil ao desenvolvimento internacional: coalizões emergentes e Cooperação Sul Sul, Revista CIDOB d'Afers Internacionals (1985), 2012; Agentes transformadores da Cooperação para o Desenvolvimento: poderes emergentes e Cooperação Sul-Sul. Relaciones internacionales (La Plata), 2011; Cooperação triangular e redes de desenvolvimento Sul Sul Norte, Redes de Cooperação, 2011. 